\title{
Tribological performance and microstructural evolution of $\alpha$-brass alloys as a function of zinc concentration
}

\author{
Zhilong LIU ${ }^{1}$, Philipp MESSER-HANNEMANN ${ }^{1}$, Stephan LAUBE ${ }^{1}$, Christian GREINER ${ }^{1,2, *}$ \\ ${ }^{1}$ Institute for Applied Materials (IAM), Karlsruhe Institute of Technology (KIT), Karlsruhe 76131, Germany \\ ${ }^{2}$ KIT IAM-CMS MikroTribologie Centrum $\mu$ TC, Karlsruhe 76131, Germany \\ Received: 05 August 2019 / Revised: 02 November 2019 / Accepted: 22 November 2019 \\ (C) The author(s) 2019.
}

\begin{abstract}
Tailoring a material's properties for low friction and little wear in a strategic fashion is a long-standing goal of materials tribology. Plastic deformation plays a major role when metals are employed in a sliding contact; therefore, the effects of stacking fault energy and mode of dislocation glide need to be elucidated. Here, we investigated how a decrease in the stacking fault energy affects friction, wear, and the ensuing sub-surface microstructure evolution. Brass samples with increasing zinc concentrations of 5, 15, and $36 \mathrm{wt} \%$ were tested in non-lubricated sphere-on-plate contacts with a reciprocating linear tribometer against $\mathrm{Si}_{3} \mathrm{~N}_{4}$ spheres. Increasing the sliding distance from 0.5 (single trace) to 5,000 reciprocating cycles covered different stages in the lifetime of a sliding contact. Comparing the results among the three alloys revealed a profound effect of the zinc concentration on the tribological behavior. CuZn15 and CuZn36 showed similar friction and wear results, whereas CuZn5 had a roughly 60\% higher friction coefficient (COF) than the other two alloys. CuZn15 and CuZn36 had a much smaller wear rate than CuZn5. Wavy dislocation motion in CuZn5 and CuZn15 allowed for dislocation self-organization into a horizontal line about $150 \mathrm{~nm}$ beneath the contact after a single trace of the sphere. This feature was absent in CuZn36 where owing to planar dislocation slip band-like features under a $45^{\circ}$ angle to the surface were identified. These results hold the promise to help guide the future development of alloys tailored for specific tribological applications.
\end{abstract}

Keywords: brass; tribology; sliding contact; microstructure; stacking fault energy; electron microscopy

\section{Introduction}

The interaction of two contacting solid surfaces is associated, in most cases, with an undesirable dissipation of energy. Approximately one-third of the world's energy resources is dissipated due to such friction processes [1]. One aim of tribology research is to reduce friction and wear and to increase energy efficiency as well as extend the lifespan of tribologically loaded parts to counteract dwindling energy resources. The European Union energy efficiency directive of 2012 called for a $20 \%$ reduction in energy consumption by 2020 [2], and an update at the end of 2016 proposed a new $30 \%$ energy efficiency target for 2030 [3]. A considerable part of this goal can be achieved through better tribological practices [4]. Copper alloys (especially brass and bronze) are favored in many engineering fields owing to their mechanical and chemical properties. Regulatory directives banning the use of heavy metals-including lead-in bearing shells and bushes $[5,6]$ have drawn additional attention to the research and development of lead-free brass alloys for tribological applications $[7,8]$.

The tribological performance of copper and copper alloys in a sliding contact has been extensively investigated in the past [9-19]. Korres et al. [10] studied the wear behavior of copper during a frictional contact with steel pins. They focused on how surface

* Corresponding author: Christian GREINER, E-mail: greiner@kit.edu 
deformation, material transfer, and wear affected topography and microstructural changes. Early studies by Taga and Nakajima [9] concerning the non-lubricated tribological behavior of brass indicated that the frictional properties of $\alpha$-brass can be enhanced by increasing the amount of zinc. Experimental contributions from Paretkar et al. [11, 12] aimed to find a defined amount of zinc in brass alloys to optimize their tribological performance; however, these studies were not successful in finding an optimal solution due to the complex nature of tribological loading.

With the continuing advance of electron microscopy, recent research in tribology has focused on the subsurface microstructure, shedding light on tribological challenges from a materials science perspective. Plastic deformation-induced microstructural changes are one of the leading causes of energy loss in a metallic tribological contact [20-22]. A resulting layered microstructure has been commonly described in the literature, with the top layer amongst other designations referred to as the "tribo-layer", "tribo-mutation layer", or the "third body" [23-26]. Bowden and Tabor [27], in a seminal contribution pointed out that friction forces in metallic contacts are determined not only by the surface topography, but also by the materials' mechanical properties. Since most hardening effects under plastic deformation of bulk materials (e.g., work-hardening and grain boundary-hardening) can be directly correlated to their microstructure, the microstructure in the sub-surface area plays a key role in determining the tribological performance of a tribo-system [28]. Rigney and Hirth [20] reported that a layer of fine-grained microstructure and preferred crystallographic orientation developed near the surface due to plastic deformation of the bulk material as a consequence of the high strain rates often associated with a sliding contact. In cases where a sub-surface nanocrystalline layer was generated during the tribological contact of two metallic solids, its microstructure and chemical composition differed significantly from the underlying bulk material [19, 29-32]. One explanation for such mixing is that the sliding contact between two solids leads to flow patterns similar to those expected in fluids [23, 33, 34]. The development of the nanocrystalline material was then driven by the generation of vortices at the intersections of the sliding bodies [23, 33-36]. Another explanation was that a localized anisotropy in polycrystalline materials leads to some grains being plastically deformed more readily compared to others [37], triggering the folding of "softer" grains upon "tougher" ones, again resulting in mechanical mixing.

When investigating the frictional behavior and microstructural changes of copper alloys, refined-grain layers with a thickness of a few micrometers and cracks parallel to the surface beneath the wear tracks have been reported $[38,39]$. With the aim of improving tribological performance, current research is increasingly focusing on the nanocrystalline regions in the subsurface area, which can be created by a strategic generation of deformation twins [40, 41]. These so-called nanotwinned materials exhibit not only high strength, but also high ductility [42]. Until now, only nanotwinned copper has been thoroughly investigated under a tribological load [43, 44].

In face-centered cubic (fcc) materials such as $\alpha$-brass, the energy threshold for twinning decreases with a reduction in stacking fault energy (SFE) [45]. The SFE is a significant factor whether dislocations move via planar or wavy slip [46, 47]. Consequently, in $\alpha$-brass alloys with an increasing zinc concentration, twinning becomes increasingly important as an elementary mechanism for plastic deformation, due to a lowering of the SFE [48, 49]. This change in SFE can have potentially dramatic effects on the tribological properties. This was already studied in the 1970s, e.g., in the Ph.D. thesis by Peter Blau [50] or by Suh and Saka [51] for single-phase fcc materials. In later decades, other materials such as biomedical steels and Co-based alloys where investigated $[52,53]$, while at the same time, Cu-based alloys were still intensively studied $[54,55]$. These research efforts led to somewhat contradictory results. While one group of authors describes a decrease in wear rate with lower stacking fault energies [55], others reported the opposite [54]. As our own research has focused on revealing the elementary mechanisms acting in a metal under a tribological load, we therefore concluded that studying the SFE effect on tribological properties of copper-zinc alloys and their microstructural evolution under a tribological load, as well as the corresponding wear mechanisms, would be a valuable addition to the existing literature. We did so by systematically changing the SFE through controlling the zinc concentration in single phase 
$\alpha$-brass alloys. We believe that this and similar data will, in the long run, help in designing materials for tribological applications as well as achieving a deeper understanding of the elementary mechanisms for the plastic deformation under tribological loading.

\section{Experimental materials and methods}

\subsection{Sample preparation}

Brass samples were obtained by Wieland-Werke AG (Ulm, Germany). Zinc concentrations of 5, 15, and $36 \mathrm{wt} \%$-corresponding with $4.8,14.6$, and 35.3 at $\%$, respectively - are chosen to achieve a decreasing SFE with increasing zinc concentration [48] (Fig. S1 in the Electronic Supplementary Material (ESM)). All three alloys (referred to as CuZn5, CuZn15, and CuZn36) are from the single phase, face-centered cubic $\alpha$-phase brass part of the $\mathrm{Cu}-\mathrm{Zn}$ phase diagram. Therefore, no influence from different phases or crystal structures was introduced. As counter bodies, polycrystalline CERBEC $\mathrm{Si}_{3} \mathrm{~N}_{4}$ spheres, provided by Saint-Gobain Ceramics (Connecticut, USA) with a diameter of $10.32 \mathrm{~mm}$, were used due to their high hardness and stiffness compared to brass.

With increasing zinc concentration and due to solid solution hardening [56, 57], the hardness of these alloys was expected to increase. This was reflected in the Vickers hardness values presented by the manufacturer (Fig. S4 in ESM). In an effort to counter this solid solution effect on hardness, the samples were annealed by holding the temperature at $550{ }^{\circ} \mathrm{C}$ and in a high vacuum $\left(1.5 \times 10^{-6} \mathrm{mbar}\right)$. The holding time were adjusted such that average starting grain sizes of $40 \mu \mathrm{m}$ for CuZn5, $50 \mu \mathrm{m}$ for CuZn15, and $77 \mu \mathrm{m}$ for CuZn36 were achieved. This increase in grain size was due to the Hall-Petch effect [58, 59] reducing the Vickers hardness difference between $\mathrm{CuZn} 5$ and CuZn36 to a factor of 1.07, while CuZn15 and CuZn36 exhibited virtually the same Vickers hardness. See Fig. S4 (ESM) for the hardness data and Fig. S10 (ESM) for the optical micrographs of the starting microstructures. After cooling down inside the furnace with an average cooling rate of $80 \mathrm{~K} / \mathrm{h}$, the samples were manually ground using $\mathrm{SiC}$ abrasive papers with different grit sizes (P800, P1200, P2500, and P4000), followed by mechanical polishing on finely woven synthetic silk clothes (provided by Cloeren Technology $\mathrm{GmbH}$, Wegberg, Germany) using monocrystalline diamond suspensions with particle sizes of 3 and $1 \mu \mathrm{m}$ (Struers, Willich, Germany). Between polishing steps, the samples were sonicated in isopropanol for $5 \mathrm{~min}$ in order to remove debris produced during the previous polishing step. The samples were electropolished with D2 electrolyte (provided by Struers) immediately before running the tribological tests. This step was critical because it removed residual scratches on the sample surfaces as well as the plastic deformation layers generated during mechanical polishing [60]. This procedure resulted in a sub-surface microstructure with the least possible defect density (as seen from the cross-sectional image presented in Fig. S2 (ESM)). When not in preparation or being tested, the samples were stored in a desiccator under vacuum to minimize environmental influences (e.g., oxidation).

\subsection{Tribological tests}

A reciprocating linear tribometer [61] was used for the non-lubricated sliding tests (Fig. S3 (ESM)). As in previous experiments on pure copper, the cycle number had been found to be a key parameter [22, 26], and the tests were run with different cycle numbers from 0.5 (single trace), through $1,10,100,500,1,000$, up to 5,000 . All other experimental parameters were held constant. A normal load of $2 \mathrm{~N}$ was applied by dead weights and the sliding speed was $0.5 \mathrm{~mm} / \mathrm{s}$. The corresponding Hertzian pressure for CuZn5, CuZn15, and CuZn36 were 542,532, and $506 \mathrm{MPa}$, respectively, calculated using the elastic properties of each material as they are listed in Table 1. Being fully aware that plastic deformation does occur in our tribological experiments, the Hertzian pressure was mainly provided to give an estimate for the contact pressure.

Table 1 Young's modulus and Poisson's ratio for CuZn5, $\mathrm{CuZn15}$, and $\mathrm{CuZn} 36$ as well as $\mathrm{Si}_{3} \mathrm{~N}_{4}$. The data is acquired from the material datasheets provided by the manufacturers (Wieland-Werke AG and Saint-Gobain Ceramics).

\begin{tabular}{ccccc}
\hline Material & $\mathrm{CuZn5}$ & $\mathrm{CuZn} 15$ & $\mathrm{CuZn} 36$ & $\mathrm{Si}_{3} \mathrm{~N}_{4}$ \\
\hline $\begin{array}{c}\text { Young's modulus } \\
(\mathrm{GPa})\end{array}$ & 127 & 122 & 110 & 320 \\
Poisson's ratio & 0.34 & 0.34 & 0.34 & 0.26 \\
\hline
\end{tabular}


A relative humidity of $50 \%$ and a temperature of $20{ }^{\circ} \mathrm{C}$ were maintained throughout all the tests. The stroke length was $12 \mathrm{~mm}$. A new $\mathrm{Si}_{3} \mathrm{~N}_{4}$ sphere was used for each test, producing a new wear track at a different position on the samples' surface. These experiments were reproduced at least twice.

In order to allow for a comparison with previous experiments performed with high purity copper against sapphire counter bodies [19, 26, 62, 63], experiments with copper against $\mathrm{Si}_{3} \mathrm{~N}_{4}$ spheres were conducted. The experimental parameters were the same as those for the brass samples. Material preparation for these copper plates was described by Ref. [26].

\subsection{Surface topography measurements}

The surface of the wear tracks was investigated with scanning electron microscopy (SEM) using a Helios NanoLab DualBeam 650 from FEI, Hillsboro, Oregon USA. To analyze the chemical composition of the bulk material and of the wear tracks, energy dispersive X-ray spectroscopy (EDS) was implemented using a X-MAX detector and the AZtecHKL software (both from Oxford Instruments, Oxford, UK). For analyzing the distribution of the elements on the wear tracks after 10, 100, and 5,000 cycles, EDS line scans perpendicular to the sliding direction were performed across the wear tracks. Non-contact 3-D scans using a Neox PLu confocal microscope (Sensofar, Terrassa, Spain) were executed to analyze the topography of the surfaces in terms of surface roughness, as well as the depth and width of the wear tracks. The area of interest for determining wear was $1.3 \mathrm{~mm}$ long along the wear track and covered the entire wear track width. This method, therefore, sampled over many features-such as hills and valleys-of the wear tracks' surface morphology and ensured representative wear values.

Since wear was expected to occur on the surface of both the brass samples and the $\mathrm{Si}_{3} \mathrm{~N}_{4}$ spheres, measuring the mass loss would not have been a representative measure to quantify wear of the brass samples. Instead, the wear volume of each wear track was determined based on optical profilometry. For this approach, we assumed that a) the wear track profile is a circle's arc, and $b$ ) the wear volume is represented by the area under the circular segment, both defined by the depth and the width of the wear track profile. A schematic diagram illustrating this method is shown in Fig. S5 (ESM).

\subsection{Microstructure investigation}

The sub-surface microstructure was investigated using a focused ion beam/scanning electron dual beam microscope (FIB/SEM, Helios NanoLab DualBeam 650). FIB cross-sections and cross-sectional TEM foils were prepared parallel to the sliding direction in the center of the wear tracks. TEM foils were prepared with a state-of-the-art lift-out technique, which allowed for site-specific TEM specimen preparation with the least number of artifacts possible [64]. Two platinum layers were deposited on the areas of interest before any ion beam milling; the first layer used the electron beam only. This ensured that the gallium ion beam did not cause damage to the microstructure being investigated by FIB cross-sections. The depth of the layered structure in the sub-surface region was measured as the mean value of five different measurements from the surface of the samples to the lower boundary of the layer. Scanning transmission electron microscopy (STEM) images were taken with an acceleration voltage of $30 \mathrm{kV}$ and a beam current of 100 pA inside the FEI Helios.

\section{Results}

\subsection{Coefficient of friction}

The coefficient of friction (COF, $\mu$ ) is the quotient of the measured friction forces divided by the applied normal load. The COFs for 5,000 reciprocating cycles and for each alloy and the copper reference are plotted as a function of the sliding cycle number in Fig. 1. For CuZn5, the COF increased by factor of two (from around 0.5 to around 1.1) for the first 500 cycles and then slightly decreased until the end of the experiment ( $\mu=0.85$ after 5,000 cycles). For CuZn15 and CuZn36, the COFs showed no significant change over the course of 5,000 cycles (with a value between 0.4 and 0.6). The COF for CuZn15 was constantly approximately 0.1 lower than that for CuZn36. CuZn5 therefore showed higher friction compared to the other two alloys by approximately one third and roughly the same as for pure copper. 


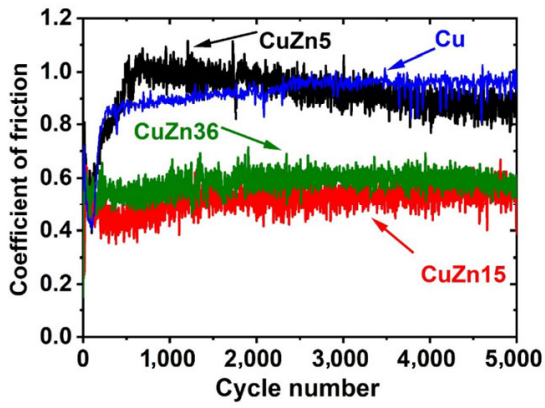

Fig. $1 \mathrm{COF}$ as a function of the cycle number during the nonlubricated reciprocating sliding of $\mathrm{Si}_{3} \mathrm{~N}_{4}$ spheres on pure copper and $\alpha$-brass samples with 5,15 , and $36 \mathrm{wt} \%$ zinc for a total of 5,000 cycles. The sliding velocity was set to $0.5 \mathrm{~mm} / \mathrm{s}$, the applied normal load to $2 \mathrm{~N}$, and the stroke length was $12 \mathrm{~mm}$. The relative humidity was kept at $50 \%$ and temperature at $20{ }^{\circ} \mathrm{C}$.

\subsection{Surface topography of the wear tracks}

The width and depth of the wear tracks as well as the wear volume are presented as a function of cycle numbers in Fig. 2. These values were determined by means of confocal microscopy. As would be expected, the width (Fig. 2(a)) and the depth (Fig. 2(b)) in each case increased with cycle number. The width of the wear tracks for all three alloys was not distinguishable for up to ten sliding cycles. With increasing sliding distance, CuZn15 and CuZn36 had the same width throughout all 5,000 cycles of loading. The wear tracks of $\mathrm{CuZn} 5$ start to be wider than the ones for the other two alloys after ten cycles, evolving twice as wide as those of CuZn15 and CuZn36 after 500 cycles loading and ending up almost three times as wide after 5,000 cycles (Fig. 2(a)). In general, the depth of the wear tracks increased with decreasing zinc content, with the only exception being CuZn15 after 1,000 cycles (Fig. 2(b)). After 5,000 cycles, the CuZn5 wear track was about 1.5 times deeper than that of CuZn36 (Fig. 2(b)). The fact that CuZn15 and CuZn36 crossed over after 1,000 cycles was most likely due to the limited number of experiments performed. With better statistics, though very challenging to achieve in tribological research, these two data points are expected to trade places. The average wear volume per stroke length was taken to evaluate the wear rate of each alloy in contact with the silicon nitride spheres (Fig. 2(c)). The wear rate for all three alloys was negatively correlated with the cycle number. With decreasing Zn
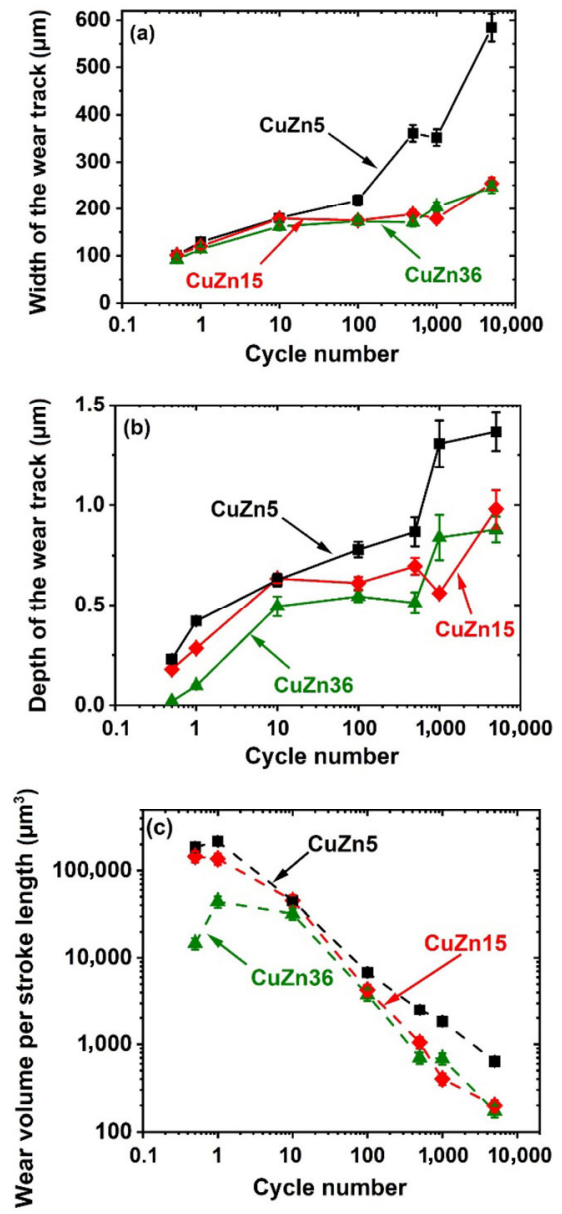

Fig. 2 (a) Width, (b) depth, and (c) wear volume for the wear tracks after non-lubricated reciprocating sliding of $\mathrm{Si}_{3} \mathrm{~N}_{4}$ spheres on $\alpha$-brass samples with 5,15 , and $36 \mathrm{wt} \%$ zinc as a function of the cycle number for a total of 5,000 cycles. The width of the wear tracks was measured using optical and the depth by confocal microscopy.

concentration (increasing SFE), the wear rate increased (Fig. 2(c)).

Figure 3 presents SEM images taken on the wear track surfaces of CuZn36 after different cycles, and compares all three alloys after 5,000 cycles. For CuZn36, after ten sliding cycles, the surface of the wear track showed grooves along the sliding direction, yet the surface generally appeared relatively smooth (Fig. 3(a)). No loose wear particles were observed for the first ten cycles. With increasing sliding cycle number (100 cycles), the wear track of CuZn36 was found to be much rougher. Deep grooves formed (Fig. 3(b)). After 5,000 cycles, sheared off flake-like wear particles were observed on the wear track of CuZn36, resembling delamination on the sample surface (Fig. 3(c), marked 


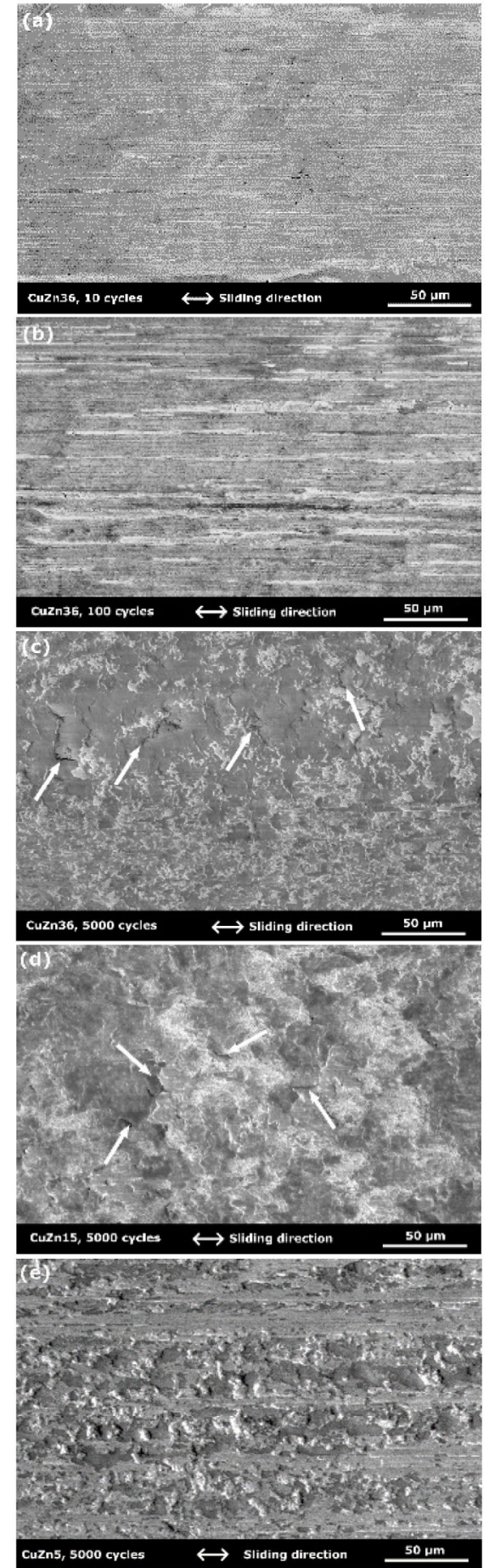

Fig. 3 SEM images of wear tracks after different cycle numbers and for different $\alpha$-brass samples illustrating the evolution of the wear tracks. (a) CuZn36 after 10 cycles, (b) CuZn36 after 100 cycles, (c) CuZn36 after 5,000 cycles, (d) CuZn15 after 5,000 cycles, and (e) CuZn5 after 5,000 cycles. (a) The entire width of the wear track is visible in the image; while (b-e) the wear tracks are so wide that the images were taken inside the wear tracks. The sliding direction is horizontal for all images and marked by white double arrows. Flake-like wear particles and delamination events are marked by the white arrows in (c) and (d). by white arrows).

Comparing the wear track surfaces of the three alloys after 5,000 cycles, CuZn36 and CuZn15 appeared similar (Fig. 3(c) and 3(d)). In contrast, the worn surface of CuZn5 appeared rougher than for CuZn15 and

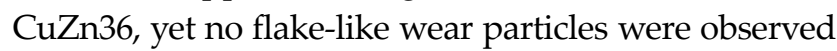
on the wear track surface (Fig. 3(e)). It should be noted that for all the three alloys, noticeable amounts of loose wear particles were found in all wear tracks after 5,000 cycles of loading. However, qualitatively significantly more loose wear particles were found on CuZn5 than on CuZn15 and CuZn36.

\subsection{Surface chemistry of the wear tracks}

EDS line scans across the wear tracks were carried out perpendicular to the sliding direction after 5,000 cycles (Fig. 4). A decreasing concentration of copper inside the wear tracks for all the three alloys was observed. The zinc concentration was found to be constant over the entire width of the wear tracks for CuZn5 and CuZn15 (Fig. 4(a) and 4(b)), maintaining the same level as outside the wear tracks. The CuZn36 wear track surface had a slightly lower zinc concentration compared to the surface outside the wear track (Fig. 4(c)). Oxygen was identified on the surface of all three wear tracks. Silicon was detected only on the wear tracks for pure copper and CuZn5, but not for CuZn15 as well as CuZn36 (Fig. 4(a)). A lower copper concentration and a higher oxygen/silicon concentration could be correlated position-wise.

The oxygen concentration inside the wear tracks is plotted in Fig. 5 for all three alloys as a function of the sliding cycle number. These values were obtained by calculating the mean value and its standard deviation over the entire width of the corresponding wear tracks (indicated by the vertical dashed lines in Fig. 4). The oxygen concentration increased with sliding cycle number from approximately $1 \mathrm{wt} \%$ after ten cycles to about $10 \mathrm{wt} \%$ after 5,000 cycles. No correlation between oxygen concentration and increasing zinc content in the alloy (from 5\% to 36\%) was observed. After 5,000 sliding cycles, the standard deviation in the case of CuZn5 was three times higher than that for CuZn15 and CuZn36.

\subsection{Sub-surface microstructure: Tribo-layers}

In order to evaluate the sub-surface microstructure 
evolution for each alloy and therefore as a function of the stacking fault energy, FIB cross-sections were cut at the center of each wear track. The contrast changes in the cross-sectional SEM images of CuZn15 in Fig. 6 demonstrate the formation and evolution of a layered sub-surface microstructure from ten up to 5,000 sliding cycles. No contrast change can be distinguished
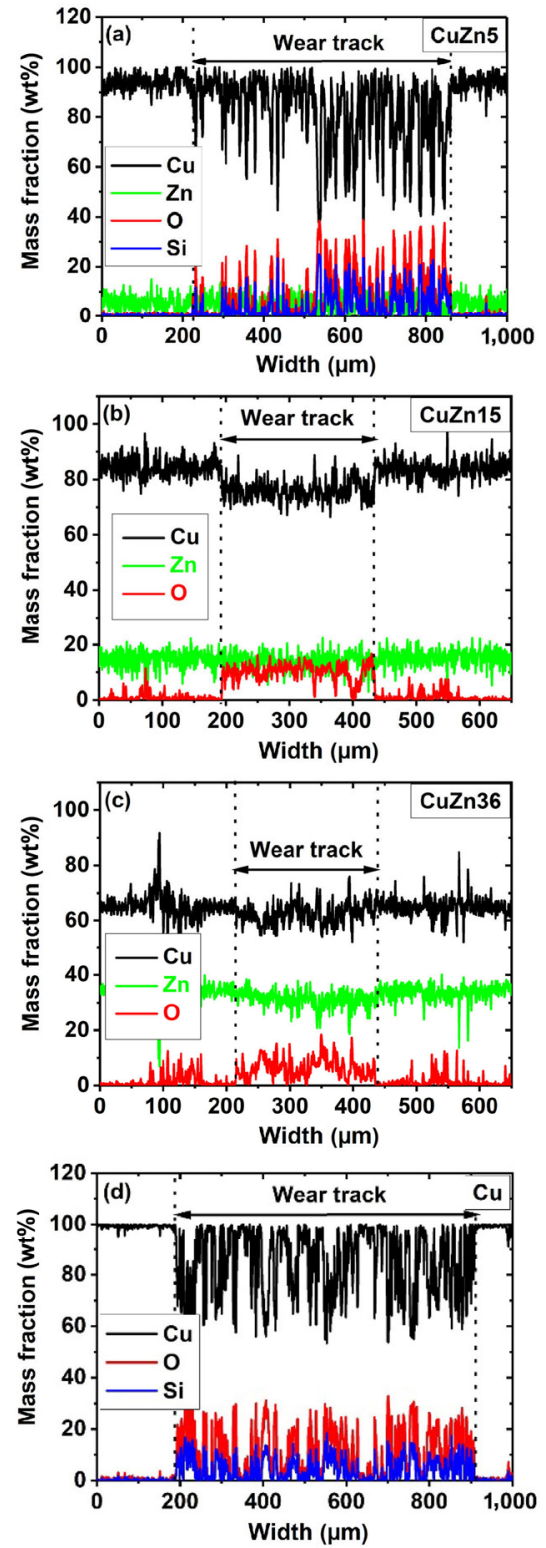

Fig. 4 Distribution of chemical elements across wear tracks after 5,000 sliding cycles for copper and $\alpha$-brass samples with 5,15 , and $36 \mathrm{wt} \%$ of zinc. Line scans perpendicular to the wear tracks were performed with a FIB/SEM DualBeam system using an EDS detector (accelerating voltage of $10 \mathrm{keV}$, beam current of $0.8 \mathrm{nA}$ ). (a) CuZn5, (b) CuZn15, (c) CuZn36, and (d) pure copper. The widths of the wear tracks are marked by vertical dashed lines and double arrows.

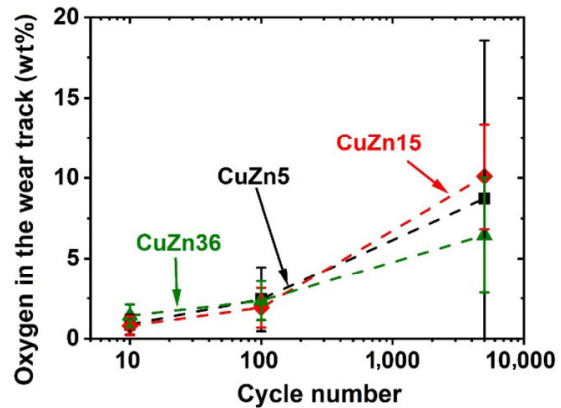

Fig. 5 Mean values for the oxygen concentration within the wear tracks of $\alpha$-brass samples with 5,15 , and $36 \mathrm{wt} \%$ of zinc after 10, 100, and 5,000 sliding cycles, respectively. Line scans perpendicular to the wear tracks were performed with a FIB/SEM DualBeam system using an EDS detector (accelerating voltage of $10 \mathrm{keV}$, beam current of $0.8 \mathrm{nA}$ ).

with the SEM in the sub-surface area earlier than ten sliding cycles. Ten cycles of tribological loading introduced slight microstructural changes right underneath the surface (Fig. 6(a)). The formation of a layer with a thickness of $130 \mathrm{~nm}$ was observed. The contrast inside this layer resembles a cell-like microstructure or sub-grains, and is therefore referred to as the "sub-grain layer" hereinafter. After 500 cycles (Fig. 6(b)), a layer with ultra-fine grained microstructure was seen for the first time, directly beneath the surface, above the sub-grain layer. The microstructure (i.e., grain size) inside this layer was so fine that SEM contrast does not offer sufficient resolution for further characterization. The top layer (located directly underneath the sample surfaces) exhibited an ultra-fine microstructure referred to as the "nanocrystalline layer." In CuZn15, both the nanocrystalline and the sub-grain layer grew in thickness with increasing sliding cycle number (Figs. 6(a)-6(d)). When the nanocrystalline layer was observed, the transition between the nanocrystalline layer and the sub-grain layer was very sharp. In contrast, there was no clear boundary between the sub-grain layer and the bulk material underneath, but rather a gradual transition in grain size.

From 10 to 500 cycles of loading, the cell-like structures inside the sub-grain layer became larger ( $1 \mu \mathrm{m}$ compared to $0.1 \mu \mathrm{m}$, respectively). The cells inside this layer appeared to be elongated toward the upper-right corner of the image. After 1,000 cycles (Fig. 6(c)), both the nanocrystalline and the sub-grain layers grew deeper into the material. Cracks (marked 
by white arrows in Fig. 6(c)) inside the nanocrystalline layer and at the sharp boundary between the two layers were seen. After 5,000 cycles (Fig. 6(d)), fewer cracks were observed compared to after 1,000 cycles. The cell boundaries inside the sub-grain layer appeared parallel to the sliding direction, in contrast to the tilted cell boundaries observed for the lower cycle number tests.

The results for CuZn5 and CuZn36 are shown in Fig. 7 after 5,000 cycles, where, in the late stages of sliding, the differences between the alloys grew more pronounced. The cross-sectional SEM images for CuZn5 and CuZn36 after 10 and up to 1,000 cycles are presented in Fig. S6 (ESM) for a pure copper sample for 5,000 cycles of the silicon nitride sphere.
The dissociation of the sub-surface microstructure into two layers was observed for all three alloys (Figs. 6, 7, and S6 (ESM)). Comparing the crosssectional microstructure for all three alloys after 5,000 cycles loading (Figs. 6(d), 7(a), and 7(b)), in CuZn5 and CuZn36, a significantly thinner nanocrystalline layer was observed, approximately $150 \mathrm{~nm}$, compared to over $300 \mathrm{~nm}$ for CuZn15. Wear particles were attached to the samples' surfaces for CuZn5 and CuZn36 (marked by white arrows in Figs. 7(a) and 7(b), respectively). This was not the case for CuZn15. The particles on the surface of CuZn5 appeared to be more spherical and the ones on the surface of CuZn36 had a flake-like appearance. Inside the nanocrystalline layer for CuZn36, some lamellar structures were
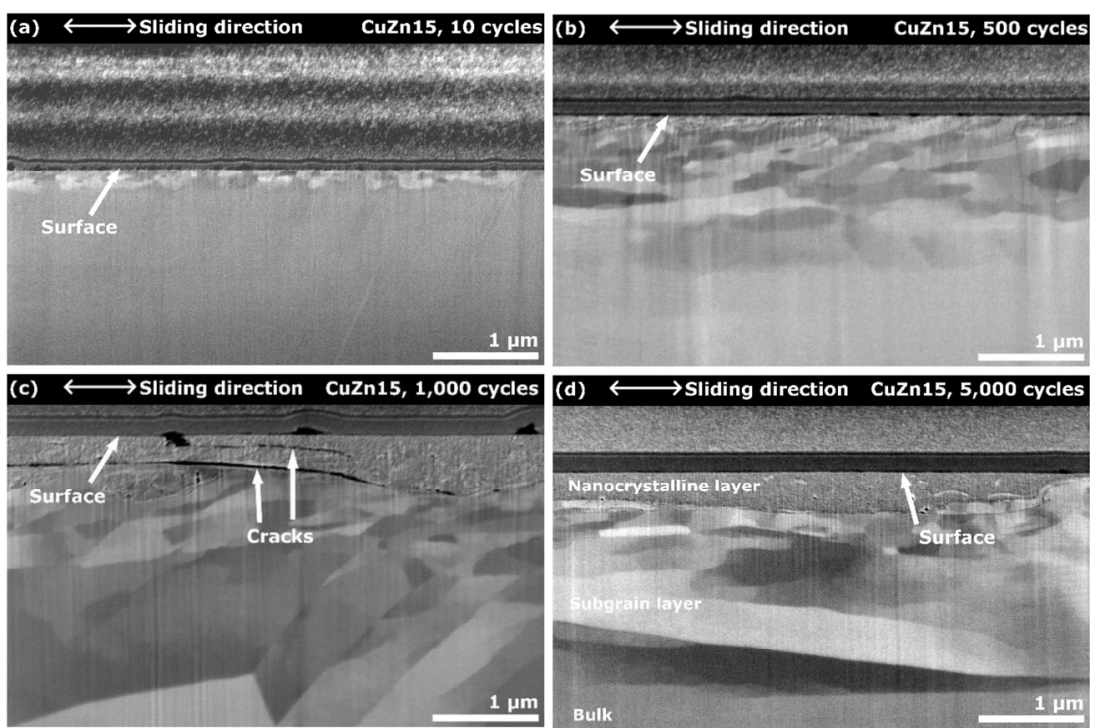

Fig. 6 Cross-sectional SEM images of the sub-surface microstructure. Microstructure evolution over different stages of sliding contact is exemplarily shown with CuZn15 (a) after 10 cycles; (b) after 500 cycles; (c) after 1,000 cycles, cracks are marked by white arrows; (d) after 5,000 cycles. The cross-sections were prepared in the center of the wear tracks, along the sliding direction (shown as the white double arrow in the images). Sample surfaces are marked by white arrows.
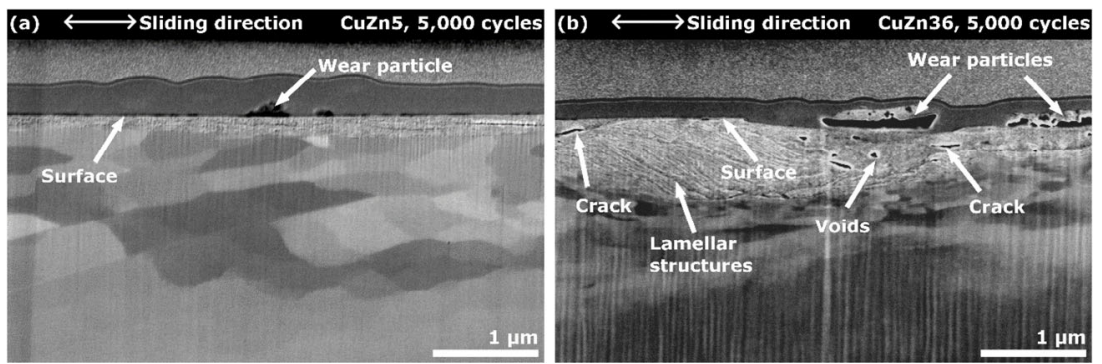

Fig. 7 Cross-sectional SEM images of the sub-surface microstructure. The microstructure in the late stage was investigated. (a) CuZn5 after 5,000 cycles, a wear particle is marked by a white arrow; (b) CuZn36 after 5,000 cycles. The cross-sections were prepared in the center of the wear track, along the sliding direction (shown as the white double arrow in the images). Sample surfaces are marked by white arrows. 
observed (Fig. 7(b), marked by a white arrow). When comparing the sub-grain layers among all three alloys in terms of their appearance, CuZn5 and CuZn15 were rather similar; both appeared less refined compared to CuZn36.

The depths of the nanocrystalline and sub-grain layers for $\mathrm{CuZn5}, \mathrm{CuZn15}$, and $\mathrm{CuZn36}$ are plotted as a function of sliding cycle number in Fig. 8. The sub-grain layer was first observed after 10 cycles of sliding for all three alloys (Fig. 8(a)), and the nanocrystalline layer occurred after 100 cycles for CuZn15 and CuZn36 and after 10 cycles for CuZn5 (Fig. 8(b)). The depth of the sub-grain layer (Fig. 8(a)), as well as the depth of the nanocrystalline layer (Fig. 8(b)) increased with the sliding cycle numbers from 10 to 1,000 cycles (sub-grain layer up to $1.42 \mu \mathrm{m}$ in CuZn5, $1.24 \mu \mathrm{m}$ in CuZn15, and $0.76 \mathrm{~mm}$ in CuZn36; nanocrystalline layer up to $120 \mathrm{~nm}$ in CuZn5, $320 \mathrm{~nm}$ in CuZn15, and $105 \mathrm{~nm}$ in CuZn36). From 1,000 to 5,000 cycles, the depth of the sub-grain layer decreased in CuZn 5 and CuZn15 by $4 \%$ and $16 \%$, respectively, and increased slightly in CuZn36 by $6 \%$. The depth of the nanocrystalline layer increased by $25 \%$ in $\mathrm{CuZn} 5$ and by $44 \%$ in CuZn36, but decreased in CuZn15 by
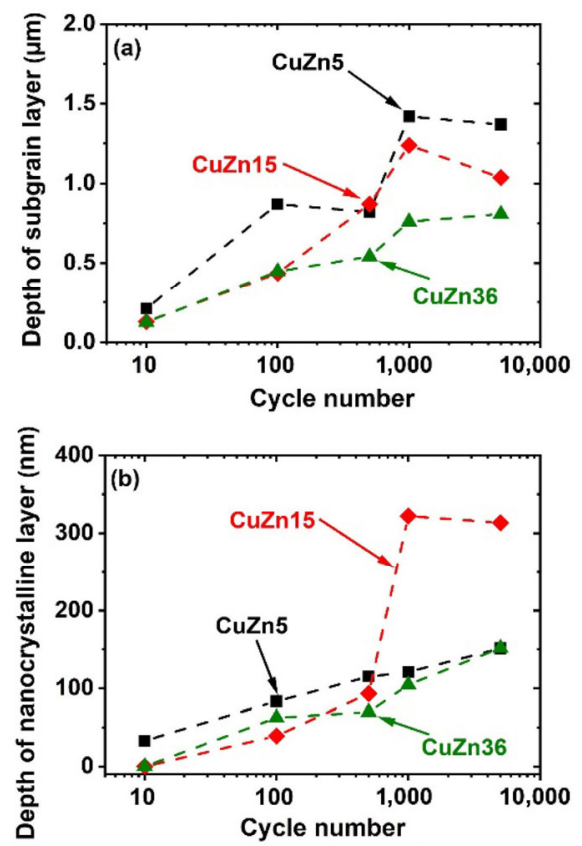

Fig. 8 Depths of the surface layers developed during the tribological loading of $\mathrm{Si}_{3} \mathrm{~N}_{4}$ spheres on $\mathrm{CuZn} 5, \mathrm{CuZn} 15$, and CuZn36 samples. The depth of (a) the sub-grain layer and (b) the nanocrystalline layer is plotted as a function of sliding cycle number, the latter on a logarithmic scale.
$3 \%$. Comparing the results from all three alloys, the depth of the sub-grain layer was found to be slightly larger for alloys with higher SFE (lower zinc concentration). For the nanocrystalline layer, no consistent trend concerning the SFE was observed. Only in the case of CuZn15 for cycle numbers of 1,000 and 5,000 were the values disproportionately higher than for CuZn5 and CuZn36.

\subsection{Sub-surface microstructure and dislocation structures}

SEM images of the sub-surface microstructures presented above demonstrated a need to further analyze the elementary processes leading to these structures. Therefore, STEM was performed on the cross-sectional areas of all three alloys at early (10 cycles) and late (5,000 cycles) stages of tribological loading (Fig. 9). Dislocation trace lines were observed for the three alloys after 10 cycles of tribological loading and are marked by white arrows. After only a single trace, such a horizontal dislocation structure was found for CuZn5 and CuZn15, but not CuZn36 (Fig. $\mathrm{S7}$ (ESM)).

In previous contributions, we revealed the dislocation trace line as a sharp line-like feature formed through a dislocation self-organization process [26, 63]. In CuZn5, multiple trace lines, with depths beneath the sliding surface from 90 to $965 \mathrm{~nm}$, were observed (Fig. 9(a)). In CuZn15 (Fig. 9(c)) and CuZn36 (Fig. 9(e)), only one dislocation trace line was found with depths of 205 and $100 \mathrm{~nm}$, respectively. In CuZn36, band-like features at an angle of $65^{\circ}$ to the sliding surface (marked by black arrow in Fig. 9(e)) were located deeper than the dislocation trace line and extending about $1 \mu \mathrm{m}$ into the sub-surface material. Such features were not observed for CuZn5 and CuZn15.

After 5,000 cycles, dislocation cells (sub-grains) were found in the sub-grain layer, which were elongated along the sliding direction. In CuZn5, the cell boundaries appeared wavy and virtually parallel to the sample surface. In CuZn15, the cell boundaries were inclined approximately $8^{\circ}$ from the sample surface towards the upper-right corner of the image. This inclination in CuZn36 is around $14^{\circ}$.

In the nanocrystalline layer of CuZn15, pores and cracks made the sample surface rough (Fig. 9(d)). 

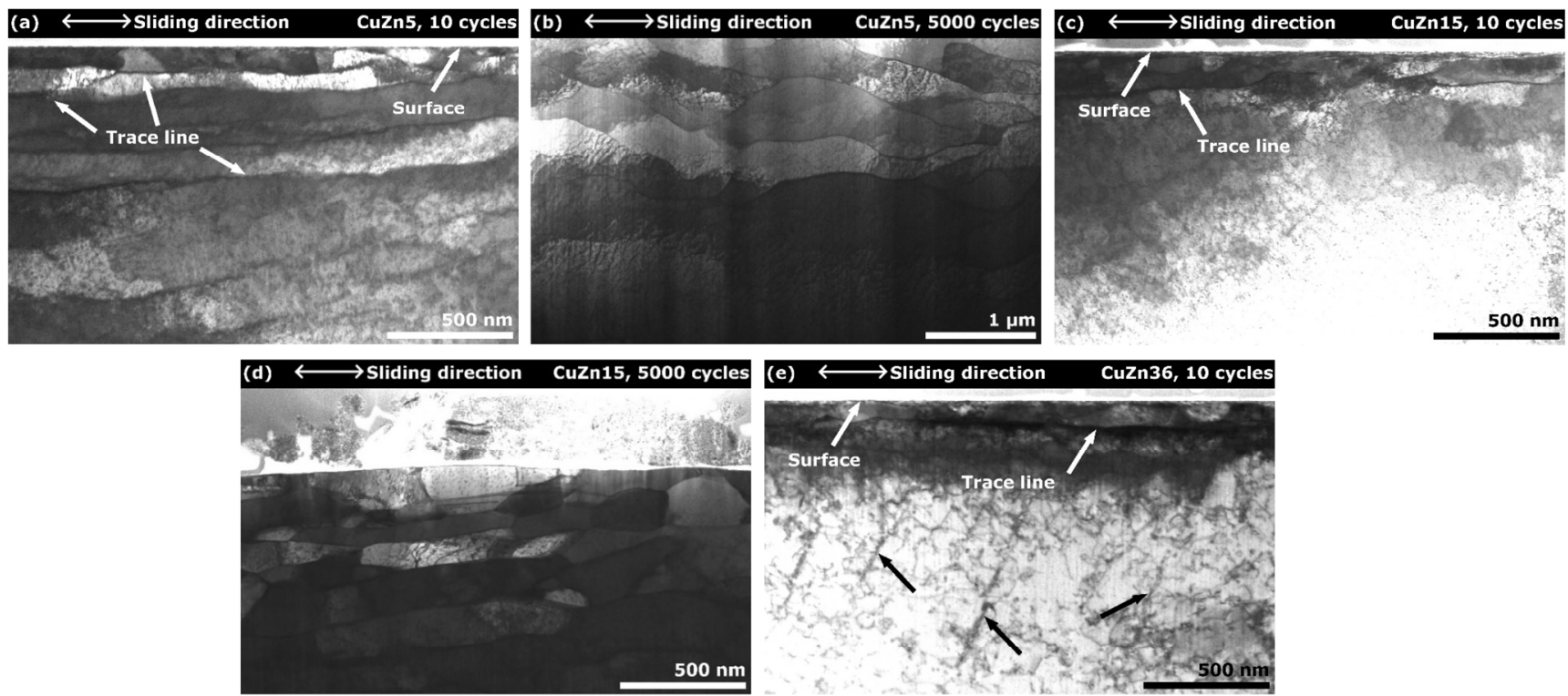

Fig. 9 Scanning transmission SEM images of the three brass alloys in early (10 cycles) and late $(5,000$ cycles) stages of tribological loading. (a) CuZn5 after 10 cycles; (b) CuZn5 after 5,000 cycles; (c) CuZn15 after 10 cycles; (d) CuZn15 after 5,000 cycles; (e) CuZn36 after 10 cycles. Slip bands are highlighted by black arrows; (f) CuZn36 after 5,000 cycles. The sample surfaces and the trace line are marked by white arrows. All TEM foils were prepared parallel to the sliding direction and perpendicular to the sliding surface (cross-sectional view).

The sharp interface seen in the center of the image (Fig. 9(d)) was the transition between the nanocrystalline and the sub-grain layer. In CuZn36, the nanocrystalline layer had a smaller grain size and was preserved as a continuous layer, in contrast to CuZn15. No cracks were found at the interface between the sub-grain and the nanocrystalline layer. There were cracks within the nanocrystalline layer. The lamellar structures inside the nanocrystalline layer were clearly resolved.

\section{Discussion}

Comparing the above presented results for the three $\alpha$-brass alloys investigated, the effect of zinc concentration and the stacking fault energy on the COF, wear track topography, surface chemistry, and sub-surface microstructure evolution will be discussed. As the literature slightly diverges on the exact values for the SFE for the alloys used in this study [48], we will, instead, concentrate on the trend of decreasing SFE with increasing zinc content.

\subsection{Friction}

CuZn5's COF increased for the first 500 cycles and then leveled off to an almost steady value, with a small decrease in friction, exhibiting a typical running-in behavior $[65,66]$. The COF for CuZn15 and CuZn36, in contrast, remained relatively constant throughout the 5,000 cycles of loading, with no sign of running-in. Comparing these results with oxygen-free highconductivity copper (OFHC) sliding against $\mathrm{Si}_{3} \mathrm{~N}_{4}$ (Fig. 1) and sapphire spheres [26] suggests that materials with relatively higher SFE exhibit a running-in process at the beginning of the lifetime of a sliding contact. In contrast, lower SFE materials do not.

Another possible explanation for these results might be based on the difference in the overall frictional behavior. Compiling eight commonly observed frictiontime-or in our case, friction-cycle number-curve shapes, Blau [67] suggested that a curve, as we measured for CuZn5, and also for pure copper [26], might often be associated with an oxidizing metal in an non-lubricated contact. While this explanation seems plausible, especially given the tendency of copper to oxidize [19], the fact that CuZn15 and CuZn36 had at least as much oxygen in the wear tracks as $\mathrm{Cu}$ and CuZn5 after 5,000 sliding cycles (Fig. 4), suggests that such an affect does not dominate.

Comparing the COFs between CuZn15 and CuZn36 
resulted in a COF $10 \%$ lower than that for $\mathrm{CuZn} 36$. At a given sliding distance, the amount of energy dissipated in the materials due to tribological loading was positively correlated with the COF [21]. This suggests that the energy dissipated during the sliding contact for CuZn36 was higher than that for CuZn15. According to literature, CuZn15 and CuZn36 are both expected to show planar slip behavior due to their relatively low SFE, indicating the tribologically induced plastic deformation might additionally have been carried by deformation twinning in both alloys $[47,48]$. This difference in COF may have been reflected in the nanocrystalline layer directly underneath the surface. CuZn15's fractured and loose nanocrystalline layer (Fig. 9(d)) may have reduced the COF compared to the robust nanocrystalline layer found in CuZn36 (Fig. 9(f)).

The effect of the SFE on friction forces has long been a challenging issue and the literature often renders controversial results $[9,50,55,68]$. This is partially due to the complex nature of any tribological contact. Other factors than SFE may also influence the COF, making systematic analyses very challenging. For example, testing the same $\mathrm{Cu}-\mathrm{Zn}$ alloys as investigated here, but against different counter bodies (stainless steel) and for a much higher sliding speed, led to a COF higher than 1.0 (in contrast to our result of $\mu=$ $0.5-0.8$ ). An opposite trend for the COF varying with SFE was previously reported by Ref. [9], while for $\mathrm{Cu}-$ $\mathrm{Al}$ alloys, a clear reduction in friction with deceasing SFE was found [55]. Even with exactly the same materials and in the same environment, the effect of the SFE has to be discussed with great caution. For example, it is not fully plausible to attribute the difference in COF between CuZn5 and CuZn15 solely to a SFE effect. The smaller micro hardness of CuZn5 compared to the other two alloys (Fig. S4 (ESM)) makes $\mathrm{CuZn} 5$ more vulnerable to abrasive wear.

\subsection{Wear}

Wear volume and the wear rate are both estimated using cross-sectional profiles of the wear tracks. As the $\mathrm{Si}_{3} \mathrm{~N}_{4}$ spheres did wear during the tests (see Fig. S8 (ESM) for optical micrographs of spheres' apexes after 5,000 sliding cycles against all three brass alloys), the wear track profiles in some instances-especially for higher cycle numbers - were not perfectly cylindrical. At the same time, our analysis was mainly intended as a comparison among the three zinc concentrations chosen, and for this purpose, our method for estimating wear was sufficiently accurate.

Concentrating on the wear rate, a monotonic increase in wear rate with SFE was observed (Fig. 2(c)). Refs. [11, 12, 53] reports that the wear resistance of $\mathrm{Cu}-\mathrm{Zn}$ alloys increases with zinc concentration from 8 to $25 \mathrm{wt} \% \mathrm{Zn}$ and improved resistance to galling with decreasing SFE. It needs to be mentioned that the opposite trend was reported for aluminum bronze alloys [54, 55], while other authors did not find any correlation [51]. We speculate that the reasoning in our case is more intricate: the much higher, exponential wear behavior of $\mathrm{CuZn} 5$ compared to the other two alloys together with the material transfer from $\mathrm{Si}_{3} \mathrm{~N}_{4}$ to $\mathrm{CuZn} 5$ distinguished $\mathrm{CuZn} 5$ from CuZn15 and CuZn36, which did not adhere to the counter-body. No satisfactory explanation as to why only CuZn15 transferred to the counter-body can be given. The higher wear rate of CuZn5 may be due to its lower hardness (around 7\% softer than CuZn15 and CuZn36, Fig. S4 (ESM)), which, as mentioned above may have led to a lower resistance to abrasive wear [69]. The exponential decrease in the wear rate may also be correlated to the development of a tribologically deformed layer (tribo-layer) in its sub-surface area, which is commonly considered to be the location where wear particles are generated in metals [37]. The formation of such a sub-surface tribo-layer has been reported in pure copper sliding against sapphire spheres in similar test environments and the layer was found to grow deeper into the material exponentially with increasing sliding cycle numbers due to the development of dislocation networks [26]. CuZn5 is expected to deform in a wavy slip mode $[47,48]$. This corresponds to the development of dislocation cells/networks in the CuZn5 sub-surface area under the sliding contact (Figs. 9(a) and 9(b)). Similar differences in dislocation motion and self-organization were reported for the fatigue behavior of copper alloys [46]. The relatively higher SFE of $\mathrm{CuZn} 5$ might accelerate the development of both tribo-layers. The data presented in Fig. 8(a) suggests that in CuZn5, the sub-grain layer indeed grew faster compared to the other two zinc concen- 
trations. The cracks at the interface between the two tribo-layers let us assume that the connection between them was weak, and in CuZn5, the detachment of larger parts of the nanocrystalline layer was possible and in agreement with the wear track as examined by SEM (Fig. 3(e)). This may have led to the observed generation of powder-like wear particles (Fig. 1(e)).

The higher amount of wear of the $\mathrm{Si}_{3} \mathrm{~N}_{4}$ spheres when in contact with $\mathrm{CuZn} 5$ may have contributed to the wear rate of CuZn5. In the literature, the wear of $\mathrm{Si}_{3} \mathrm{~N}_{4}$ when in contact with copper during hot wire rolling has been reported to be a tribochemical wear process, in which silica $\left(\mathrm{SiO}_{2}\right)$ forms and detaches from the $\mathrm{Si}_{3} \mathrm{~N}_{4}$ surface. CuZn5 has the highest concentration of copper (95\%) among the three alloys we tested and is thus expected to behave more similarly to pure copper than the other two alloys. It is therefore reasonable to assume a higher tribochemical reactiveness for CuZn5. The observation of $\mathrm{Si}$ on the surface of CuZn5 after 5,000 cycles of loading (Fig. 4(a)) is in agreement with this assumption.

The comparison between CuZn15 and CuZn36 is more directly connected to a SFE effect. Both alloys had approximately the same micro hardness and did not exhibit any transferred $\mathrm{Si}$ on the wear track surfaces. The lower wear rate of CuZn36 than CuZn15 agreed very well with results reported in Ref. [54]. Planar slip during deformation led to the formation of slip bands and twin boundaries, both depending on the crystallographic orientation of the grains. The nanocrystalline layer appeared to be equiaxial in CuZn15 (Fig. 6(d)), similar to that in CuZn5 (Fig. 7(a)). In CuZn36, some lamellar structures were observed inside the nanocrystalline layer (Figs. 7(b) and 9(f)). In a material deforming via planar-slip (i.e., CuZn36), stacking faults and twining are additional mechanisms to the formation of dislocation cells. The line-like features with an angle to the sliding surface observed in Fig. 9(e) are a first sign of this change in dislocation behavior. Compared to the random orientation of dislocation cells, lamellar structures were then formed in the nanocrystalline layer of CuZn36 at a late stage of sliding. We speculate that cracks initiated at and propagated along the boundaries of these lamellar structures, resulting in more flake-like wear particles (Fig. 7(b)). Such orientated deformation features on a non-textured polycrystalline surface may be obstacles to the formation of a tribo-layer parallel to the sliding surface. The hindered formation of a tribo-layer may slow the wear rate.

Looking at the problem from an energetic point of view, the energy in the contact was dissipated either to deform the materials, or used to create new free surfaces for loose wear particles (not accounting for frictional heating). These two dissipation pathways are in competition with each other. The higher friction of CuZn36 indicates more work was done in this system. Combining this with its lower wear rate suggests that the microstructural changes in CuZn36 absorbed more dissipated energy, leading to less wear. This, again, is in agreement with the kinetics for the growth of a sub-grain layer as indicated in Fig. 8(a) and the overall smaller wear rate of $\mathrm{CuZn} 36$.

\subsection{Surface chemistry}

When analyzing the surface chemistry, oxygen was expected inside the wear tracks as the concept of tribologically induced oxidation has long been established [19, 72, 73]. Through such a mechanically and chemically driven process, oxygen enters the brass surface and, with continuing sliding, oxides are formed [19]. This is the reason behind the increasing oxygen concentration with sliding cycle numbers as presented in Fig. 5. The rather high standard deviation of these EDS measurements (Fig. 5), especially after 5,000 cycles, hints at an increase in surface roughness and a non-uniform distribution of the surface layer, e.g., as indicated in Fig. 3(e) for CuZn5.

Interestingly, for all the three alloys after 5,000 cycles, it was found that wherever the oxygen concentration increased, the copper concentration decreased while the mass fraction of zinc remained roughly the same (Fig. 4). This indicates that, especially for CuZn5 and CuZn15, copper oxides were preferred to zinc oxides and were then removed as loose wear particles [37]. This might also explain why, for these two alloys, and in contrast to CuZn5 and pure copper, no silicon was detected on the wear track surfaces. Perhaps the material that transferred from the counter-body was fully incorporated into the wear particles. This hypothesis is supported by the fact that silicon was detected by EDS in wear particles collected from an 
experiment conducted with pure copper (Fig. S9 (ESM)). At the same time, it is as conceivable that, owing to currently unknown surface chemistry effects, there is no transfer from the counter-body onto the CuZn15 and CuZn36 wear tracks. This assumption is further substantiated by the apparent correlation between sharp dips (or valleys) in the copper concentration and peaks in the oxygen mass fraction profile observed in Fig. 4(a). This is in contrast to the sometimes reported dezincification in brass alloys containing $15 \%$ or more of zinc [74]. For CuZn36 (Fig. 4(c)), both copper and zinc were equally reduced in their respective mass fractions.

Between the brass alloys, silicon was only detected on the wear track of $\mathrm{CuZn} 5$ after 5,000 cycles, indicating a material transfer from the $\mathrm{Si}_{3} \mathrm{~N}_{4}$ sphere to the sample surface. This is supported by the fact that the $\mathrm{Si}_{3} \mathrm{~N}_{4}$ spheres were found to wear the most for CuZn5 experiments (Fig. S8 (ESM)). Doğan and Hawk [75] reported that the matrix grain size and grain boundaries in $\mathrm{Si}_{3} \mathrm{~N}_{4}$ strongly influenced its abrasive wear behavior. It is therefore reasonable to assume that during the CuZn5 experiments, $\mathrm{Si}_{3} \mathrm{~N}_{4}$ particles detached from the sphere. Some of these particles were transferred to the CuZn5 surfaces due to a higher concentration of copper, leading to stronger adhesion when in contact with $\mathrm{Si}_{3} \mathrm{~N}_{4}$ [70].

\subsection{Sub-surface microstructure}

There are clear differences in the sub-surface microstructural evolution for the three brass alloys being investigated. Since great care was taken to keep test parameters constant for all experiments and hardness increases due to solid solution strengthening were attempted to be balanced by an increase in grain size, a main differentiating characteristic between these alloys is their stacking fault energy.

Similar to our previous results on copper and nickel [63], in all three brass alloys, a so-called dislocation trace line was observed after ten reciprocating sliding cycles (Fig. 9). The formation of the dislocation trace lines was previously explained by a sign change in the stress field in the tribologically loaded sample induced by the sliding contact [63]. This contact mechanics explanation-as a first approximation - was irrespective of crystal orientation and resulted in a dislocation self-organization parallel to the sliding surface [63]. It was therefore to be expected to observe this dislocation self-organization feature in all three alloys. At the same time, and in agreement with recent dislocation dynamics modeling for pure indentation [76] and for tribological loading [77], dislocation cross-slip might be necessary for the formation of the trace line. Owing to the factor of six reduction in stacking fault energy for CuZn36 compared to CuZn5, yielding a wider splitting of partial dislocations, crossslip is significantly more energetically unfavorable in CuZn36. This is reflected in the fact that while the trace line was observed after a single trace of the silicon nitride sphere for CuZn5 and CuZn15, this was not the case for CuZn36 (Fig. S7 (ESM)). We hypothesize that the energy necessary to form a dislocation trace line is higher in CuZn36 compared to the other two alloys and its formation does take place in CuZn36, but at a slower rate compared to the other two alloys. This might explain the slightly higher friction forces for CuZn36 during the very initial stages of the sliding contact (Fig. 1). Interestingly, the band-like structures seen in CuZn36 after a single trace had an angle to the sliding surface of $42^{\circ}$ (Fig. S7 (ESM)). This is very close to $45^{\circ}$ and therefore suggests that the maximum shear stresses dominated dislocation movement [78]. At the same time one needs to keep in mind that under a tribological load, the stress-state is complex and these $45^{\circ}$, as they are commonly observed for tension or compression experiments, cannot easily be transferred. Once dislocations have started to move on a specific slip system and due to cross-slip, they are not sufficiently able to react to the changing stress field under the sphere as it is the case in higher stacking fault energy materials such as copper [77, 79], where a trace line is already formed after a single trace [63].

Differences in SFE also showed their significant influence on the microstructure at depths beyond the first dislocation trace line. In CuZn5, several trace lines parallel to the sliding surface were observed (Fig. 9(a)), in contrast to CuZn15 and CuZn36, where only one trace line was found (Fig. 9(c) and 9(d)). This difference may have been due to the ease of cross-slip for the predominant wavy-slip in CuZn5. Interestingly, in CuZn36 (Fig. 9(e)), besides the dislocation trace line, 
we also observed parallel line features angled $65^{\circ}$ to the sample surface after ten cycles. These features have a resemblance to structures previously reported for predominantly planar slip materials under a tribological load [52] and dislocation features known to evolve during fatigue [46]. Instead of self-organizing into the dislocation trace line parallel to the sliding surface, dislocations concentrated on specific slip planes, forming slip bands in CuZn36. These structures most likely are not twins, which would be an alternative explanation. However, detailed (high resolution) transmission electron microscopy is needed to confirm this point. In contrast to what we had observed after only one trace (Fig. S7 (ESM)), the angle of these slip bands changed from approximately $45^{\circ}$ to $65^{\circ}$. This might either be an indication that the maximum shear stress induced by the sliding sphere had changed as sliding progressed, or-more likely-that the entire crystal under the contact had rotated.

The sub-surface microstructure for the later stages of the sliding contact, after 5,000 cycles (Figs. 6 and 7), is very different to that in the beginning. However, the characteristics of the microstructure evolution specific to each alloy, which had already manifested itself after ten sliding cycles, are again apparent during the later stages. Each alloy exhibited a distinct sub-surface grain morphology. For CuZn5 (Fig. 7(b)), the sub-surface grains were elongated along the sliding direction. It is reasonable to assume that the new (sub-) grain boundaries, separating these grains, are a further evolution of the trace lines formed at the very beginning of sliding (Fig. 9(a)). In CuZn15, the grains showed a more equiaxial appearance, especially compared to those in CuZn36. However, the general trend of grains elongated in sliding direction persisted in all three alloys. In CuZn36, these grains were not perfectly parallel to the sliding surface, but angled under $8^{\circ}$. The reason for this alignment might be found in the slip band-like features seen after 0.5 and 10 sliding cycles. These might have further developed into new grain boundaries and carried some of their angles to the surface into the later stages of the microstructure evolution.

Surprisingly, when comparing the sub-surface microstructure evolution of the three alloys with experiments conducted with pure copper in contact with a sapphire sphere [26], one finds that CuZn15 exhibits a sub-surface microstructure with the most similarities to pure copper. This might be explained by the fact that for CuZn5, the microstructure was, early on, influenced by the generation of wear particles. This was not the case for the pure copper experiments. In the case of CuZn36, its significantly reduced stacking fault energy results in a different dislocation self-organization phenomena, i.e., the appearance of slip bands-like structures.

Two distinctly different layers were observed in the sub-surface area of all three brass alloys (Fig. 6). The one directly under the sliding contact was identified as the "nanocrystalline layer," due to grain sizes $<50 \mathrm{~nm}$. The layer directly underneath was identified as the "sub-grain layer." The contrast changes inside this layer observed in the SEM images presented in Fig. 6 are interpreted as small angle grain boundaries and the cell-structures as sub-grains [26].

The refinement of the microstructure in the sub-grain layer and the growth of this layer deeper into the material with increasing sliding cycle number are observed in Figs. 6, 7, and 9. This behavior suggests an accumulation of plastic strain and therefore, dislocation activity in the sub-surface area. For a given sliding cycle number, the higher the SFE, the deeper the sub-grain layer grows into the material (Fig. 8(a)). The formation of dislocation cells thus requires larger plastic strains. This consequently slows the grain refinement process and therefore the growth of the sub-grain layer during tribological loading (Fig. 2). In CuZn5, cross-slip of dislocations is expected to occur easier, allowing for the rapid formation of dislocation cells [68], therefore leading to a sooner grain refinement and faster growth of the sub-grain layer.

In contrast to the sub-grain layer, the depth of the nanocrystalline layer (Fig. 8(b)) does not show a clear trend with SFE. This might be explained by the fact that in this very near surface layer, the plastic shear imposed by the tribological load was so high that the mode of dislocation glide does not matter. All three alloys offer sufficient independent slip systems to accommodate the plastic shear and did so by forming a nanocrystalline layer. As of now, no satisfactory explanation for the significantly different behavior at 
higher cycle numbers of CuZn15 compared to the other two alloys can be offered. This might be due to the fact that, especially for CuZn5, a considerable amount of loose wear particles was generated. Assuming that these wear particles had their origin in the nanocrystalline layer, our method of measuring the thickness of the nanocrystalline layer is not an accurate assessment of all the nanocrystalline material generated due to tribological loading.

When comparing the results in this study to those obtained with pure copper in contact with a sapphire sphere under otherwise very similar conditions [26], for pure copper, no separate nanocrystalline layer was observed. We speculate that this difference can be attributed to the different counter-bodies used in these experiments. The sapphire spheres that were sliding against the pure copper samples never showed any signs of wear [26], whereas the $\mathrm{Si}_{3} \mathrm{~N}_{4}$ spheres employed here did wear significantly for CuZn5 and less for CuZn15 and CuZn36 (Fig. S8 (ESM)). While in our EDS analysis of the wear tracks for CuZn15 and CuZn36, no silicon was found, the mere existence of wear particles within the contact dramatically changed the mechanics of the contact itself. The local stresses at the sliding surface differed, leading to different deformation mechanisms. It is important to note that irrespective of zinc content, and therefore of stacking fault energy, our sub-surface microstructural data strongly suggests that all three alloys mainly deformed through dislocation motion. Within the limits of the microstructure characterization methods applied here, no evidence for twinning was found.

It is well-documented in the literature that tribologically induced sub-surface grain refinement is achieved through the accumulation and subsequent self-organization of dislocations. When Emge et al. [32] investigated the non-lubricated frictional behavior of 440C stainless steel pins in contact with OFHC, they found a gradient of increasing grain sizes in the sub-grain layer with increasing distance from the contacting surface. This is in good agreement with what we report here. Similarly, Heilmann et al. [82] described a layer of refined grains immediately below the surface of OFHC. They reported that the grain boundaries became more diffuse and less sharp as the depth below the surface increased. This is exactly what was observed for the brass samples within this study (Fig. 6(b)). The nanocrystalline layer reported here is similar in appearance to the lamellar structure described by Korres et al. [10]. These authors performed lubricated experiments with a steel pin sliding on copper samples. According to their results, the nanocrystalline layer developed due to the repeated material delamination and re-deposition during the ploughing of the pin on the sample surface, leading to a pile-up of material forming lamellar structures (similar to Fig. 7(b)). Korres at al. [10] also described the development of a nanocrystalline and a sub-grain layer, separated by a sharp discontinuity in the sub-surface area. They considered this discontinuity to be the precursor of voids and cracks and therefore to be the origin of wear generation. This is, in very good agreement with what we report here for the three brass alloys under investigation. This line of argumentation is seconded by Rigney and Glaeser [83], who argued that the large amount of boundaries within the nanocrystalline layer are favorable for the formation of voids and cracks. For all three brass alloys, voids and cracks were observed inside the nanocrystalline layer (Figs. 6 and 7) and especially at the interface between the nanocrystalline and the sub-surface layer. This suggested that wear particles originated from and consumed the nanocrystalline layer.

\section{Conclusions}

The tribological performance and sub-surface microstructure evolution of three $\alpha$-brass alloys ( $\mathrm{Cu}$ with 5, 15 , and $36 \mathrm{wt} \% \mathrm{Zn}$ ) were systematically investigated in order to reveal a possible influence of the stacking fault energy. Friction, wear, surface chemistry, material transfer, and the formation of tribologically induced microstructural changes were characterized in nonlubricated reciprocating sliding contacts against $\mathrm{Si}_{3} \mathrm{~N}_{4}$ spheres for an increasing number of sliding cycles (from 0.5 to 5,000 ). Within these alloys, the stacking fault energy decreased by about a factor of six with increasing zinc concentration. Our results are summarized as follows:

1) CuZn5 (the highest SFE) exhibited running-in behavior and had a roughly $60 \%$ higher coefficient of 
friction than CuZn15 and CuZn36.

2) Over the course of 5,000 sliding cycles, the wear rate for CuZn5 was approximately $70 \%$ higher compared to CuZn15. This might be attributed to a $56 \%$ decrease in SFE as well as changes in hardness due to solid solution strengthening.

3) Material transfer from the $\mathrm{Si}_{3} \mathrm{~N}_{4}$ sphere to the sample surface was found in the late stage of the sliding contact (after 5,000 cycles) for CuZn5, whereas there was no material transfer for CuZn15 and CuZn36.

4) CuZn15 and CuZn36 showed very similar friction and wear behavior for all cycle numbers, and in all cases lower values than for CuZn5. This is most probably due to planar slip dominating dislocation motion with decreasing stacking fault energy. For CuZn5, mechanical mixing between brass and material from the counter-body $\left(\mathrm{Si}_{3} \mathrm{~N}_{4}\right.$ or $\left.\mathrm{SiO}_{2}\right)$ took part and greatly accelerated wear particle formation.

5) CuZn36 had the most stable surface chemistry in terms of oxygen and silicon entering the material. At the same time, this difference may very well only have been an indirect effect of the stacking fault energy and might have to do with the wear behavior as well as subtle differences in hardness.

6) The sub-surface microstructure evolved into two distinctly different layers. Directly under the surface, a layer with nanocrystalline grains formed, followed by a sub-grain layer. Both were separated by a sharp boundary. The depth of both layers increased with sliding cycle number. The grain size within the sub-grain layer decreased as sliding progressed. With increasing stacking fault energy, the sub-grain layer grew faster into the material. In the initial stages of sliding, a similar trend was observed for the nanocrystalline layer.

7) Due to a transition from wavy to planar slip with decreasing stacking fault energy, different dislocation structures evolved in the sub-surface area of the three brass alloys. For CuZn5 and CuZn15, already after a single trace, a dislocation trace line was formed. For CuZn36, this feature evolved later (after ten cycles), while after a single trace, band-like structures at an angle of approximately $45^{\circ}$ to the surface were found. This is most probably due to the highest shear stress acting under this angle and cross-slip in CuZn36 slowing the formation of a dislocation trace line.
8) These differences in dislocation motion and selforganization carry on to the late stages of sliding, resulting in equiaxed grains within the nanocrystalline layer for CuZn5 and CuZn15, whereas CuZn36 exhibited elongated grains inside the nanocrystalline layer. This, in turn, led to powder-like wear particles for CuZn5 and CuZn15. In CuZn36, a lamellar structure inside the nanocrystalline layer developed, leading to flake-like wear particles.

\section{Acknowledgements}

Christian GREINER acknowledges funding by the German Research Foundation under Project GR 4174/1 and by the European Research Council (ERC) under Grant No. 771237, TriboKey. The authors thank Dr. Johannes SCHNEIDER for discussion and a critical reading of the manuscript.

Electronic Supplementary Material Supplementary material is available in the online version of this article at https://doi.org/10.1007/s40544-019-0345-8.

Open Access This article is licensed under a Creative Commons Attribution 4.0 International License, which permits use, sharing, adaptation, distribution and reproduction in any medium or format, as long as you give appropriate credit to the original author(s) and the source, provide a link to the Creative Commons licence, and indicate if changes were made.

The images or other third party material in this article are included in the article's Creative Commons licence, unless indicated otherwise in a credit line to the material. If material is not included in the article's Creative Commons licence and your intended use is not permitted by statutory regulation or exceeds the permitted use, you will need to obtain permission directly from the copyright holder.

To view a copy of this licence, visit http://creativecommons.org/licenses/by/4.0/.

\section{References}

[1] Holmberg K, Erdemir A. Influence of tribology on global energy consumption, costs and emissions. Friction 5(3): 263-284 (2017) 
[2] European Comission. Directive 2012/27/EU of the european parliament and of the council. Off $J$ the Eur Union 315: 1-56 (2012)

[3] European Comission. Commission Proposes New Rules for Consumer Centred Clean Energy Transition. European Comission (2016).

[4] Carpick R W, Jackson A, Sawyer W G, Argibay N, Lee P, Pachon A, Gresham R M. Can tribology save a quad. Tribol Lubr Technol 72: 44-45 (2016)

[5] European Comission. Commission directive 2011/37/EU. Off J the Eur Union 85 : 3-7 (2011)

[6] European Comission. Directive 2000/53/EC. Off $J$ the Eur Union 269: 34-43 (2000)

[7] Laumann S, Jisa R, Deinhofer G, Franek F. Tribological properties of brass materials and their application for cages in rolling bearings. Tribol-Mater, Surf Interfaces 8(1): 35-40 (2014)

[8] Liu L, Zhang Z C, Dienwiebel M. The running-in tribological behavior of $\mathrm{Pb}$-free brass and its effect on microstructural evolution. Tribol Lett 65: 160 (2017)

[9] Taga Y, Nakajima K. Friction and wear of $\mathrm{Cu}-\mathrm{Zn}$ alloys against stainless steel. Wear 37(2): 365-375 (1976)

[10] Korres S, Feser T, Dienwiebel M. In situ observation of wear particle formation on lubricated sliding surfaces. Acta Mater 60(1): 420-429 (2012)

[11] Paretkar R K, Modak J P, Ramarao A V. An approximate generalized experimental model for dry sliding adhesive wear of some single-phase copper-base alloys. Wear 197(1-2): 17-37 (1996)

[12] Mindivan H, Çimenoğlu H, Kayali E S. Microstructures and wear properties of brass synchroniser rings. Wear 254(5-6): 532-537 (2003)

[13] Liu T. Sliding friction of copper. Wear 7(2): 163-174 (1964)

[14] Marui E, Endo H. Effect of reciprocating and unidirectional sliding motion on the friction and wear of copper on steel. Wear 249(7): 582-591 (2001)

[15] Chen X, Han Z, Li X Y, Lu K. Lowering coefficient of friction in $\mathrm{Cu}$ alloys with stable gradient nanostructures. Sci $A d v$ 2(12): 1601942 (2016)

[16] Chen X, Han Z, Lu K. Enhancing wear resistance of Cu-Al alloy by controlling subsurface dynamic recrystallization. Scr Mater 101: 76-79 (2015)

[17] Sadykov F A, Barykin N P, Aslanyan I R. Wear of copper and its alloys with submicrocrystalline structure. Wear 225-229: 649-655 (1999)

[18] Kong X L, Liu Y B, Qiao L J. Dry sliding tribological behaviors of nanocrystalline $\mathrm{Cu}-\mathrm{Zn}$ surface layer after annealing in air. Wear 256(7-8): 747-753 (2004)

[19] Liu Z L, Patzig C, Selle S, Höche T, Gumbsch P, Greiner C.
Stages in the tribologically-induced oxidation of high-purity copper. Scr Mater 153: 114-117 (2018)

[20] Rigney D A, Hirth J P. Plastic deformation and sliding friction of metals. Wear 53(2): 345-370 (1979)

[21] Shakhvorostov D, Pöhlmann K, Scherge M. An energetic approach to friction, wear and temperature. Wear 257(1-2): 124-130 (2004)

[22] Greiner C, Gagel J, Gumbsch P. Solids under extreme shear: Friction-mediated subsurface structural transformations. Adv Mater 31(26): 1806705 (2019)

[23] Rigney D A, Karthikeyan S. The evolution of tribomaterial during sliding: A brief introduction. Tribol Lett 39(1): 3-7 (2010)

[24] Ren F, Bellon P, Averback R S. Nanoscale self-organization reaction in $\mathrm{Cu}-\mathrm{Ag}$ alloys subjected to dry sliding and its impact on wear resistance. Tribol Int 100: 420-429 (2016)

[25] Wolff K, Liu Z L, Braun D, Schneider J, Greiner C. Chronology of the microstructure evolution for pearlitic steel under unidirectional tribological loading. Tribol Int 102: 540-545 (2016)

[26] Greiner C, Liu Z L, Strassberger L, Gumbsch P. Sequence of stages in the microstructure evolution in copper under mild reciprocating tribological loading. ACS Appl Mater Interfaces 8(24): 15809-15819 (2016)

[27] Bowden F P, Tabor D. The Friction and Lubrication of Solids. Oxford (UK): Clarendon Press, 1950.

[28] Argibay N, Chandross M, Cheng S, Michael J R. Linking microstructural evolution and macro-scale friction behavior in metals. J Mater Sci 52(5): 2780-2799 (2017)

[29] Rigney D A. Transfer, mixing and associated chemical and mechanical processes during the sliding of ductile materials Wear 245(1-2): 1-9 (2000)

[30] Li J, Elmadagli M, Gertsman V Y, Lo J, Alpas A T. FIB and TEM characterization of subsurfaces of an Al-Si alloy (A390) subjected to sliding wear. Mater Sci Eng A 421(1-2): 317-327 (2006)

[31] Emge A, Karthikeyan S, Kim H J, Rigney D A. The effect of sliding velocity on the tribological behavior of copper. Wear 263(1-6): 614-618 (2007)

[32] Emge A, Karthikeyan S, Rigney D A. The effects of sliding velocity and sliding time on nanocrystalline tribolayer development and properties in copper. Wear 267(1-4): 562-567 (2009)

[33] Luo Z P, Zhang G P, Schwaiger R. Microstructural vortex formation during cyclic sliding of $\mathrm{Cu} / \mathrm{Au}$ multilayers. $\mathrm{Scr}$ Mater 107: 67-70 (2015)

[34] Pouryazdan M, Kaus B J P, Rack A, Ershov A, Hahn H. Mixing instabilities during shearing of metals. Nat Commun 8(1): 1611 (2017) 
[35] Subramanian K, Wu J H, Rigney D A. The role of vorticity in the formation of tribomaterial during sliding. In MRS Proceedings. Cambridge: Cambridge University Press, 2004.

[36] Karthikeyan S, Kim H J, Rigney D A. Velocity and strain-rate profiles in materials subjected to unlubricated sliding. Phys Rev Lett 95(10): 106001 (2005)

[37] Beckmann N, Romero P A, Linsler D, Dienwiebel M, Stolz U, Moseler M, Gumbsch P. Origins of folding instabilities on polycrystalline metal surfaces. Phys Rev Appl 2(6): 064004 (2014)

[38] Feser T, Stoyanov P, Mohr F, Dienwiebel M. The running-in mechanisms of binary brass studied by in-situ topography measurements. Wear 303(1-2): 465-472 (2013)

[39] Moshkovich A, Perfilyev V, Lapsker I, Rapoport L. Friction, wear and plastic deformation of cu and $\alpha / \beta$ brass under lubrication conditions. Wear 320: 34-40 (2014)

[40] Balogh L, Ungár T, Zhao Y H, Zhu Y T, Horita Z, Xu C, Langdon $\mathrm{T}$ G. Influence of stacking-fault energy on microstructural characteristics of ultrafine-grain copper and copper-zinc alloys. Acta Mater 56(4): 809-820 (2008)

[41] Zhang Y S, Wang K, Han Z, Liu G. Dry sliding wear behavior of copper with nano-scaled twins. Wear 262(11-12): 14631470 (2007)

[42] Li X Y, Dao M, Eberl C, Hodge A M, Gao H. Fracture, fatigue, and creep of nanotwinned metals. MRS Bull 41(4): 298-304 (2016)

[43] Wu Z X, Zhang Y W, Srolovitz D J. Dislocation-twin interaction mechanisms for ultrahigh strength and ductility in nanotwinned metals. Acta Mater 57(15): 4508-4518 (2009)

[44] Singh A, Tang L, Dao M, Lu L, Suresh S. Fracture toughness and fatigue crack growth characteristics of nanotwinned copper. Acta Mater 59(6): 2437-2446 (2011)

[45] Venables J A. The nucleation and propagation of deformation twins. J Phys Chem Solids 25(7): 693-700 (1964)

[46] Wang Z R. Cyclic deformation response of planar-slip materials and a new criterion for the wavy-to-planar-slip transition. Philos Mag 84(3-5): 351-379 (2004)

[47] Gerold V, Karnthaler H P. On the origin of planar slip in f.c.c. Alloys. Acta Metall 37(8): 2177-2183 (1989)

[48] Gallagher P C J. The influence of alloying, temperature, and related effects on the stacking fault energy. Metall Trans 1(9): 2429-2461 (1970)

[49] Staroselsky A, Anand L. Inelastic deformation of polycrystalline face centered cubic materials by slip and twinning. J Mech Phys Solids 46(4): 671-673, 675-696 (1998)

[50] Blau P J. A study of the interrelationships among wear, friction and microstructure in the unlubricated sliding of copper and several single-phase copper alloys. Ph.D. Thesis. Columbus (USA): The Ohio State University, 1979.
[51] Suh N P, Saka N. The stacking fault energy and delamination wear of single-phase f.c.c. metals. Wear 44(1): 135-143 (1977)

[52] Fischer A, Weiß S, Wimmer M A. The tribological difference between biomedical steels and cocrmo-alloys. J Mech Beh Biomed Mater 9: 50-62 (2012)

[53] Bhansali K J, Miller A E. The role of stacking fault energy on galling and wear behavior. Wear 75(2): 241-252 (1982)

[54] Wert J J, Singerman S A, Caldwell S G, Quarles R A. The role of stacking fault energy and induced residual stresses on the sliding wear of aluminum bronze. Wear 91(3): 253-267 (1983)

[55] Feller H G, Gao B. Correlation of tribological and metal physics data: The role of stacking fault energy. Wear 132(1): 1-7 (1989)

[56] Friedel J. Dislocations. Oxford (UK): Pergamon Press, 1964.

[57] Labusch R. A statistical theory of solid solution hardening. Phys Status Solidi B 41(2): 659-669 (1970)

[58] Hall E O. The deformation and ageing of mild steel: III discussion of results. Proc Phys Soc Sect B 64(9): 747-753 (1951)

[59] Petch N J. The cleavage strength of polycrystals. J Iron Steel Inst 174(1): 25-28 (1953)

[60] Beilby G T. Surface flow in crystalline solids under mechanical disturbance. Proc Roy Soc Lond 72: 218-225 (1903)

[61] Greiner C, Schäfer M, Popp U, Gumbsch P. Contact splitting and the effect of dimple depth on static friction of textured surfaces. ACS Appl Mater Interfaces 6(11): 7986-7990 (2014)

[62] Chen X, Schneider R, Gumbsch P, Greiner C. Microstructure evolution and deformation mechanisms during high rate and cryogenic sliding of copper. Acta Mater 161: 138-149 (2018)

[63] Greiner C, Liu Z L, Schneider R, Pastewka L, Gumbsch P. The origin of surface microstructure evolution in sliding friction. Scr Mater 153: 63-67 (2018)

[64] Mayer J, Giannuzzi L A, Kamino T, Michael J. TEM sample preparation and FIB-induced damage. MRS Bull 32(5): 400-407 (2007)

[65] Blau P J. On the nature of running-in. Tribol Int 38(11-12): 1007-1012 (2005)

[66] Blau P J. Running-in: Art or engineering? J Mater Eng 13(1): 47-53 (1991)

[67] Blau P J. Friction Science and Technology: From Concepts to Applications. 2nd edn. Boca Raton (USA): CRC Press, 2009.

[68] Wert J J, Cook W M. The influence of stacking fault energy and adhesion on the wear of copper and aluminum bronze. Wear 123(2): 171-192 (1988)

[69] Archard J F. Contact and rubbing of flat surfaces. J Appl 
Phys 24(8): 981-988 (1953)

[70] Khader I, Hashibon A, Albina J M, Kailer A. Wear and corrosion of silicon nitride rolling tools in copper rolling. Wear 271(9-10): 2531-2541 (2011)

[71] Akdogan G, Stolarski T A. Wear in metal/silicon nitride sliding pairs. Ceram Int 29(4): 435-446 (2003)

[72] Yao S H, Su Y L, Kao W H, Liu T H. Tribology and oxidation behavior of TiN/AlN nano-multilayer films. Tribol Int 39(4): 332-341 (2006)

[73] Stott F H. The role of oxidation in the wear of alloys. Tribol Int 31(1-3): 61-71 (1998)

[74] Panagopoulos C N, Georgiou E P, Simeonidis K. Lubricated wear behavior of leaded $\alpha+\beta$ brass. Tribol Int 50: $1-5$ (2012)

[75] Doğan C P, Hawk J A. Microstructure and abrasive wear in silicon nitride ceramics. Wear 250(1-12): 256-263 (2001)

[76] Gagel J, Weygand D, Gumbsch P. Formation of extended prismatic dislocation structures under indentation. Acta Mater 111: 399-406 (2016)

[77] Gagel J, Weygand D, Gumbsch P. Discrete dislocation

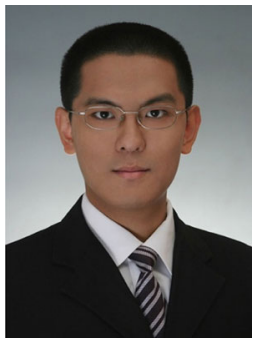

Zhilong LIU. He conducted his doctoral research in materials science and obtained his doctoral degree from the Department of Mechanical Engineering in the Karlsruhe Institute of Technology (KIT) in 2017, Germany. After his postdoctoral research at

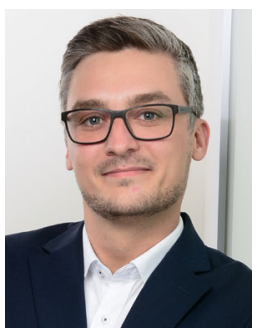

Philipp MESSER-HANNEMANN. He received his B.Sc. and M.Sc. degrees in mechanical engineering from the Karlsruhe Institute of Technology, Germany, focusing on material science and medical

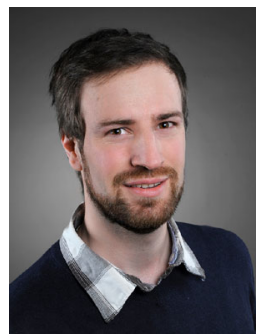

Stephan LAUBE. He obtained his M.S. degree in 2018 from the Department of Mechanical Engineering, Karlsruhe Institute of Technology (KIT), Germany. He is currently a research associate under the super- dynamics simulations of dislocation transport during sliding. Acta Mater 156: 215-227 (2018)

[78] Hull D, Bacon D J. Introduction to Dislocations. Oxford (USA): Butterworth-Heinemann, 2011.

[79] Hamilton G M. Explicit equations for the stresses beneath a sliding spherical contact. Proc Inst Mech Eng Part C J Mech Eng Sci 197(1): 53-59 (1983)

[80] Hughes D A, Hansen N. Graded nanostructures produced by sliding and exhibiting universal behavior. Phys Rev Lett 87(13): 135503 (2001)

[81] Hughes D A, Hansen N. Exploring the limit of dislocation based plasticity in nanostructured metals. Phys Rev Lett 112(13): 135504 (2014)

[82] Heilmann P, Clark W A T, Rigney D A. Orientation determination of subsurface cells generated by sliding. Acta Metall 31(8): 1293-1305 (1983)

[83] Rigney D A, Glaeser W A. The significance of near surface microstructure in the wear process. Wear 46(1): 241-250 (1978)

the Max-Planck-Institut für Eisenforschung $\mathrm{GmbH}$, he is currently working in Carl Zeiss Microscopy $\mathrm{GmbH}$ in Germany since 2018. His research interests range from materials' microstructure characterization under tribological loading to advanced applications and technology of electron microscopy.

engineering. Currently he is a Ph.D. student at the Institute of Biomechanics at the Hamburg University of Technology, Germany. His research interests include the material characterization of medical implants and the optimization of implantation process during total hip arthroplasty.

vision of Prof. Martin Heilmaier. His research interest centers on the mechanical behavior of high entropy alloys (HEAs) at elevated temperatures. His current research is on the development of refractory metalbased compositionally complex alloys (CCAs) with improved mechanical properties. 


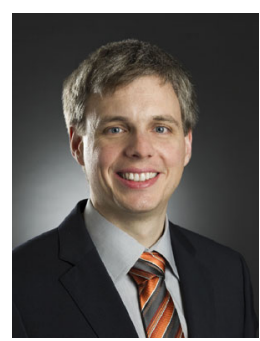

Christian GREINER. He obtained his M.S. degree from the University of Stuttgart in 2004 and his Ph.D. from the Max Planck Institute for Metals Research in 2007, Germany. After a postdoc at the University of Pennsylvania, he joined the
Karlsruhe Institute of Technology (KIT), Germany, in 2010. He heads the materials tribology group, mainly funded through a Consolidator Grant of the European Research Council (ERC). His research interests include microstructure property relations under a tribological load as well as bioinspired surface morphologies. 